\title{
Thromboprophylaxis Measures to Prevent Venous Thromboembolism in Hospitalized Patients
}

\author{
Dilceu Silveira Tolentino Júnior $^{1 * \circledast}$, Roberto Carlos de Oliveira ${ }^{2}$ \\ ${ }^{1}$ Faculty of Medicine, Federal University of the Jequitinhonha and Mucuri Valleys, Teófilo Otoni, Minas Gerais, Brazil \\ ${ }^{2}$ Vale do Rio Doce University, Governador Valadares, Minas Gerais, Brazil
}

\section{*Correspondence to \\ Dilceu Silveira Tolentino Júnior, \\ Email: dilceujunior@bol.com.br}

Received December 5, 2020 Accepted December 10, 2020 Published online December 30, 2020

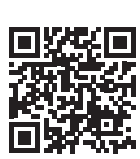

Please cite this article as follows: Tolentino Júnior DS, Oliveira RCD. Thromboprophylaxis measures to prevent venous thromboembolism in hospitalized patients. Int J Basic Sci Med. 2020;5(4):118124. doi:10.34172/ ijbms.2020.21.

\begin{abstract}
Venous thromboembolism (VTE) is a serious complication in hospitalized patients and is the most frequent cause of preventable death in these patients, in addition to being the third cause of death of cardiovascular origin. Even though the loss of recent or continued mobility represents an important predisposition related to the onset of VTE, there are no clear and uniform criteria for defining the concept of immobility. Despite this, it is currently known that the early mobilization and other non-pharmacological thromboprophylactic measures of the patient in the medical or surgical clinic is an essential measure for his full recovery and satisfactory prognosis. Therefore, it is always important to prescribe preventive multiprofessional care, such as lateral decubitus variation, bed positioning, passive continuous movements apparatus as use of a cycle ergometer (CE), compressive socks, intermittent pneumatic compression (IPC), electric stimulation, sitting position, orthostatism, transfer from bed to chair, walking, and insertion of a filtering device in the lower portion of the main human vein in order to guarantee recovery quickly, safely and free from the risk of developing fatal complications such as pulmonary thromboembolism (PTE). Our objective in this article is to briefly summarize the main non-pharmacological thromboprophylaxis measures that help prevent venous embolism, in addition to addressing other mechanical resources used to prevent complications of thromboembolic events described in the literature on this topic.

Keywords: Venous thromboembolism, Early mobilization, Thromboprophylaxis, Nonpharmacology measures, Inpatients
\end{abstract}

\section{Introduction}

Non-pharmacological mechanical measures are a set of effective procedures and resources used by health professionals to prevent thromboembolic events in low, moderate and high risk patients who are hospitalized. ${ }^{1}$ Kinesiotherapy in the hospital environment is one of the most important thromboprophylactic measures to be implemented, and aims to maintain or increase the muscular and vascular function of the patient, based on orthostasis, transfer, and ambulation. ${ }^{2}$

Pulmonary thromboembolism (PTE) consists of acute obstruction of pulmonary artery circulation by the installation of blood clots, usually from the systemic venous circulation, with reduction or cessation of pulmonary blood flow to the affected area. ${ }^{3}$ These interrelated conditions are the main acute clinical complication and have high rates of death and illness, especially in the least developed regions of the world. ${ }^{4}$

Thromboembolism risk for hospitalized patients is especially high, it is estimated that for every 20 hospitalized patients, about one patient will suffer fatal pulmonary embolism, due to the individual characteristics of the patients, the comorbidities that lead to hospitalization and the therapeutic interventions used. Therefore, adequate prophylaxis for venous thromboembolism (VTE) is necessary. ${ }^{5}$

Nowadays, the prophylaxis of VTE has its efficacy and its cost benefit proven by several studies. Numerous protocols are available to all health professionals so that the prophylaxis of venous thrombosis is applied routinely and correctly in all hospitals. However, it is known that despite all the information available, prophylaxis

(C) 2020 The Author(s); Published by Zabol University of Medical Sciences. This is an open-access article distributed under the terms of the Creative Commons Attribution License (http://creativecommons.org/licenses/by/4.0), which permits unrestricted use, distribution, and reproduction in any medium, provided the original work is properly cited. 
is not being used satisfactorily in many institutions. ${ }^{6}$ The objective of this work was to describe the main non-pharmacological thromboprophylaxis measures published by the scientific community so far for the control of VTE.

\section{Defining Immobility}

Different definitions were used to characterize immobility, especially from a qualitative point of view, being described as a dichotomous variable (mobile or restricted), or in levels (partial or total); in addition to the quantitative point of view, with descriptions of walking time or distance covered in 24 hours. ${ }^{7}$ The terms reduced mobility, prolonged immobility, confinement to bed or rest with the privilege of going to the bathroom are used as synonyms for immobility. ${ }^{8}$

Thrombotic diseases can manifest in different locations of the venous system, however these conditions are more frequently observed in lower limbs, resulting from immobilization in the bed for prolonged periods, with the incidence of these events in $80 \%$ to $95 \%$ of cases. ${ }^{9}$

\section{Early Mobilization}

Early mobilization has been considered safe and viable, and rarely causes adverse reactions, it should be applied daily, both in stable, bedridden and unconscious patients. ${ }^{10}$ The improvement in functional status, with leaving the bed and early walking, and the decrease in hospital stay, are positive indicators promoted by the motor approach. ${ }^{11}$ There are many barriers faced for the realization of early mobilization, such as the absence of material resources, adequate staff, apprehension with maintaining a risk-free environment for the health and well-being of patients, in addition to the lack of data on the effectiveness and importance of the technique. ${ }^{12}$

Certainly, early mobilization is a therapy that brings physical and psychological benefits and avoids the risks of prolonged hospitalization, decreasing the incidence of pulmonary thromboembolic complications, accelerating recovery and reducing the time of mechanical ventilation, being considered a therapy that optimizes functional recovery, particularly during the first days of hospitalization. ${ }^{13}$

\section{Indications for Non-pharmacological}

Thromboprophylaxis Measures According to the Patient's Degree of Risk

Prophylactic conduct is already considered an old action, however, today the correct measure of prophylaxis in the treatment of immobilized patients has not yet been performed, justifying the increasing mortality rate in the hospital environment. ${ }^{14}$

On the other hand, the use of drug prophylaxis is greater among clinical patients, when compared to surgical patients, which may occur mainly due to the concern of health professionals with bleeding risk. ${ }^{15}$
It is reported that thromboprophylaxis should be maintained for a period of 6 to 14 days and should not be neglected for patients with walking ability, requiring prophylaxis according to their risk classification. Patients classified as low risk for VTE do not need medication prophylaxis, with early ambulation being the only prophylactic indication, however, it is necessary to reassess the patient every two days. ${ }^{16}$

Patients classified as moderate to high risk, who have contraindications to the use of drug prophylaxis, can benefit from mechanical methods. If these resources are not available in the hospital, some simple measures can be taken, such as the elevation of the lower limbs, considered a useful measure in the prophylaxis of VTE in addition to not generating expenses for the health system. ${ }^{17}$

The use of anticoagulant drugs may present risks for bleeding, which will depend on the intensity of the treatment, the combined use with other anticoagulant, thrombolytic or antiplatelet drugs, in addition to the patient's characteristics and comorbidities. ${ }^{18}$

Thrombosis prophylaxis should be indicated for hospitalized patients, acute clinicians, older than 40 years, with impaired mobility or some other predisposition associated to thromboembolic diseases. Individuals under age of 40 may benefit from prophylaxis if there are important risk factors. ${ }^{16}$

The passive distribution of protocols and the dissemination of isolated thromboprophylaxis strategies have a low probability of success. The integration of simple models of thromboembolic risk with hospital prescriptions is an essential strategy to increase the protection of hospitalized patients. ${ }^{13,14}$ Based on effectiveness and relationship in terms of cost-effectiveness of the intervention, the thromboprophylaxis protocols in selected patients presented in Box 1 is the one that stand out most as a hospital patient protection practice, mainly because it mixs mechanical/drug assistance to avoid VTE in the wards, in the post-anesthetic recovery rooms, and especially in the intensive care units. ${ }^{14}$

\section{Contraindications for Non-pharmacological Thromboprophylactic Measures \\ Despite the evaluated benefits, mechanical methods may present difficulties in installation or maintenance, as they limit the patient's movement. Some contraindications are imposed on mechanical prophylaxis, such as: lower limb infection, severe heart failure, peripheral arterial failure, open fractures and lower limb ulcer. ${ }^{19,20}$}

\section{Non-invasive Mechanical Measures}

Among the activities performed by nursing and physiotherapy in intensive care units are changes in decubitus and positioning in the bed, passive mobilizations, free active-assisted and active exercises, electric stimulation, functional exercises, portable device to self-exercise, and early walking. ${ }^{1}$ 
Box 1. Priorities for the Implementation of Thromboprophylaxis Recommendations in Surgical Patients

\section{National Institute for Clinical Excellence (NICE) proposal}

Evaluation of patients to identify thromboembolic risk;

Provide oral and written information to the patient about the importance of preventing these events, before surgery;

- Offer to selected patients of elastic stockings graduated, compressive, since hospital admission; Make associated use of IPC, cycle ergometer and compressive elastic stockings;

Supply of medicated thromboprophylaxis with LMWH, in high-risk thromboembolic patients and in

orthopedic surgical patients, in association with mechanical thromboprophylaxis;

Maintenance of drug thromboprophylaxis for 1 month after hip arthroplasty;

Avoiding anesthetic induction through inhalation and venous routes;

Encourage the surgical patient to walk as early as possible.

Abbreviations: LMWH, low molecular weight heparin; VTE, venous thromboembolism; IPC, intermittent pneumatic compression.

There have been studies in which the most frequent type of mobilization was walking, along with sitting at the bedside or in the armchair. Although the mobilization percentages are different in the studies, this has not been indicative of an increase in adverse events. ${ }^{21}$

Therefore, some articles indicate early mobilization for surgical and clinical patients due to the risk of developing deep venous thrombosis (DVT). This practice is more approached and recommended in low-risk patients. ${ }^{22}$ As for high and medium risk, the prophylaxis verified was exclusively medication, be it surgical or clinical priority. Since the biggest failure is in medium-risk patients. ${ }^{22}$

Some protocols were created and compared, for example, the Modified Sandri and Sandri/DavisonCaprini protocols are mentioned, whose comparison identified that in patients of medium, high and low risk pre and post surgical intervention, early mobilization is indicated together with external resources such as pneumatic compression, elastic stockings in the preanesthetic induction period, up to the daily ambulation stage. Besides these strategies, drug prevention is proposed only for high-risk patients. ${ }^{23}$

Compressive Socks

Elastic or inelastic compression is the application of a force on an area of the body surface. The term elastic stockings therapeutic (synonym: medical sock, compression sock or elastic stocking) indicates a compression profile determined in vitro, with the maximum pressure at the ankle, decreasing in the direction of the thigh in millimeter of mercury - mm Hg (standard unit for elastic compression measurements). ${ }^{24}$

Compression stockings are classified into support, preventive or prophylactic stockings (below $15 \mathrm{~mm}$ $\mathrm{Hg}$ ); therapeutic elastic stockings (over $15 \mathrm{~mm} \mathrm{Hg}$ ) and anti-thrombotic stockings (18 at $23 \mathrm{~mm} \mathrm{Hg}$ ). ${ }^{25}$ The prescription of an elastic stocking, performed in a medical prescription, must contain ankle, calf and thigh thickness measurement, knee and hip height; type of sock to be worn (below the knee, above the knee, pants or pregnant women); indication of the level of compression in millimeters of mercury, in addition to the frequency, intensity and duration of use. ${ }^{26}$

An adaptation period is required at the beginning of use, and it is very important for the prescriber to emphasize to his patient that therapeutic elastic stockings are the best option for clinical management in the face of a vascular pathological event. Formal contraindications for the use of elastic stockings are: peripheral arterial disease, septic phlebitis, skin infections of the lower limbs, incompatibility with the material of compression stockings (allergy), lymphangitis, erysipelas, skin eczema, advanced peripheral neuropathy, heart failure decompensated, ankle/leg disproportion. ${ }^{26}$

The three major outcomes of VTE are pulmonary embolism, PTS and phlegmasia dolens. ${ }^{27}$ The use of therapeutic elastic stockings, routinely indicated immediately after confirmation of DVT is strongly associated with a decreased chance of developing this syndrome. ${ }^{28,29}$ However, the type of sock, as well as start, time of application and duration of use are still not well determined. ${ }^{28-31}$

\section{Intermittent pneumatic compression}

Intermittent pneumatic compression (IPC) has been widely indicated for individuals with the objective of avoiding VTE after the postoperative period, ${ }^{32,33}$ being also useful in the intraoperative stage, and in that mediate perioperative period, when immobility of the hospitalized individual is intense. ${ }^{34}$

The mechanism of CPI is based on the increase in blood circulation of the vasculature of the legs and feet and on the induction of fibrinolytic activity in the bloodstream, in addition to the induction of fibrinolysis in the blood circulation. ${ }^{34}$

The device usually includes an air pump in the foot, foot and leg, or leg and thigh. Through sequential insufflation of cuffs, involving the feet to the calf, IPC significantly increases the venous flow and has fibrinolytic action. It is highly effective. It can replace or be added to antithrombotic drug regimens. ${ }^{35}$ 
The pressure in the IPC device ranges from 35 to 55 $\mathrm{mm} \mathrm{Hg}$, which inflates in cycles of 20 to 90 seconds, respectively, in the ankle, knee and thigh, increasing the flow speed in the femoral vein by $240 \%$. When only one chamber is used, at the ankle, with a pressure of 35 $\mathrm{mm} \mathrm{Hg}$, for 12 seconds, this increase is $180 \%$. There is evidence that this form of prophylaxis increases activity endogenous fibrinolytic. ${ }^{36,37}$

Formal contraindication to the device is the presence of severe peripheral arterial disease leading to limb ischemia. Obviously, pneumatic compression in these cases can further worsen the site perfusion. In addition, care should be taken in patients who have been bedridden for more than 72 hours without using any type of DVT prophylaxis. In these cases, IPC may be responsible for displacing thrombi already formed in the lower limbs. What can be done in this situation is, before using the device, perform Doppler ultrasonography of the lower limbs to rule out the presence of thrombi. ${ }^{37}$

\section{Neuromuscular Electrical Stimulation}

Neuromuscular electrical stimulation (NMES) is an action of therapeutic electrical stimuli exerted on the musculature, from the peripheral nervous system, which restores motor and sensory functions ${ }^{38} \mathrm{NMES}$ is a method that induces the growth of skeletal muscle, in addition to increasing the strength and resilience of patients in patients who are unable to perform active exercises. Thus, it becomes a way to prevent the loss of muscle mass. ${ }^{39,40}$ This technique is used in research and in the clinical part for rehabilitation, it can be used for recovery and conservation of muscle mass and function. ${ }^{41-43}$

\section{Orthostatic Board}

Orthostasis is a therapeutic resource indicated to readapt individuals to assume the upright position in the moment that is not possible to maintain this position efficiently. ${ }^{44}$ This practice, in addition to preventing blood stasis, consequently prevents thrombotic processes in the cardiovascular system, improves oxygenation, increases ventilation, improves alertness, vestibular stimulation, prevents joint contracture and pressure ulcers. ${ }^{45}$

\section{Cycle ergometer}

Cycle ergometer (CE) is an immobile instrument that provides cyclical rotating movements, besides being useful for the performance of physical activities performed both passively and actively, according to the resistance of each patient. ${ }^{43}$ This device is also widely indicated for salutary individuals, in addition to being used in a set of theories and practices that benefit the preservation of the thigh muscle thickness during prolonged immobilizations. Despite its frequent use in an outpatient setting to assist in the individuals recovery carriers of chronic obstructive pulmonary disease. ${ }^{46}$ There is a limited number of studies that evaluate the use of this important therapeutic resource in the nosocomial environment, especially in the areas of intensive care. ${ }^{47-49}$

Current research shows that the CE can also become useful for patients at risk of developing thromboembolism, and in cases of subacute and chronic stroke, brain injury, chronic degenerative neurological diseases, and spinal cord injury. Commercially available CEs show major varieties, both structurally and functionally, being able to positively impact the specific recovery of patients who use it. $^{50}$

Invasive Mechanical Measures and Insertion of Inferior Vena Cava Filter

The filters are implanted, mostly, under the aid of fluoroscopy and with the use of iodinated contrasts in a specific sector, but the alternative for individuals who require greater complexity of transport, in addition to using contrast is the implant carried out with the aid of test that uses high frequency sound waves to measure the amount of blood flow in the arteries and veins. ${ }^{51}$

Obtaining an extraction index of redeemable filters remains minimum, a fact that must be related to the general state of health of each polytrauma patient, in addition to failure in the postoperative follow-up of the patient by the service that implanted it. ${ }^{52}$

The permanent insertion of this resource in the vena cava lumen is highly efficient to prevent PTE however, some complications may arise, presenting a significant rate of thrombosis that can lead to severe post-thrombotic complications. ${ }^{53,54}$ Thus, the provisional discontinuation of the vena cava by this resource in cases of trauma seems be the option of choice in the prevention of PTE, especially in cases where there is a contraindication to full anticoagulation. ${ }^{55}$

Traditionally, IVC filters have been suggested for individuals with acute PTE related to the use of anticoagulants. ${ }^{56}$ They are also used in recurrences of PTE, despite adequate anticoagulation, as well as in the presence of massive PTE and in surgical cases of embolectomy. ${ }^{57}$

More recently, especially with the advent of removable filters, its indication has been extended to patients affected by proximal DVT with high temporary risk for PTE. ${ }^{58}$ In recent years, due to the higher prevalence of thrombi originating from the upper extremities, filters have also been used installed in the superior vena cava. ${ }^{59}$

Using this feature should be considered, specially for patients who will undergo surgery and those affected by a thrombotic event in the last 30 days, for which anticoagulation should be stopped. ${ }^{60,61}$ Removable filters should be used in individuals who have temporary restrictions on anticoagulants, and should remain for approximately 2 weeks. ${ }^{62}$

Continuous use of these filters therapeutically is not indicated for patients not selected with DVT and candidates for the use of anticoagulants. They should 
be used in individuals who have a problem with the anticoagulant therapy or who have a recurrence despite adequate pharmacological treatment. Patients with permanent filters, after the anticoagulant contraindication has passed, should receive this therapy additionally. ${ }^{62}$

Complications related to the permanent use of these filters are common. Early complications include thrombosis of the puncture site, as well as recurrence of DVT and late post-thrombotic syndrome. More than $20 \%$ of individuals develop IVC occlusion after half a decade, and 33\% after almost 10 years without any direct relationship with the regimen and type of anticoagulant medication. ${ }^{63}$

\section{Conclusion}

Thromboembolic events mainly affect hospitalized patients, as they are often restricted to the bed, with reduced walking and limb movement, in addition to other comorbidities associated with hospitalization. VTE is considered the most preventable factor for in-hospital deaths. These deaths can be prevented by identifying and stratifying risk factors, in addition to the correct mechanical and pharmacological prophylaxis to be used, providing safety and well-being to patients.

Despite the existence of guidelines and protocols, these preventive measures for early mobilization and use of non-pharmacological thromboprophylaxis are still underutilized due to the reduced knowledge of professionals involved with patient care. However, it is essential that there is greater awareness on the part of health professionals regarding the risks and the proper prevention of thromboembolism, through training and educational strategies in order to awaken them to the problems caused by the disease.

In addition, it is possible to notice that currently there is little availability of studies that address nonpharmacological thromboprophylactic measures. Despite the great importance of this theme, most of the studies found are isolated and outdated, and few were randomized and controlled studies that aimed to study the mechanical treatment of patients with thromboembolic events and their benefits. It remains clear that most researchers prefer to study the pharmacological treatment of these events, failing to contribute to cost-effective and safe measures for both patients and the health system.

\section{Ethical Approval \\ Not applicable.}

\section{Conflict of Interest Disclosure}

The authors declare that there are no competing interests.

\section{Funding/Support}

None.

\section{Authors' Contribution}

DSTJ and RCO contributed to the drafting, literature review, critical review, and article writing. The author read and approved the final version of the manuscript.

\section{References}

1. Informs meeting calendar. INFORMS J Appl Anal. 2017;47(2):C3-C3. doi:10.1287/inte.2017.v47n2.c3

2. FMD, Dantas CM, Lopez A. et al. A influência da mobilização precoce no tempo de internamento na Unidade de Terapia Intensiva. ASSOBRAFIR Ciência. 2012; 3(2): 31-42.

3. Barrios D, Rosa-Salazar V, Morillo R, et al. Prognostic significance of right heart thrombi in patients with acute symptomatic pulmonary embolism: systematic review and meta-analysis. Chest. 2017;151(2):409-416. doi:10.1016/j. chest.2016.09.038

4. Weeda ER, Kohn CG, Fermann GJ, et al. External validation of prognostic rules for early post-pulmonary embolism mortality: assessment of a claims-based and three clinicalbased approaches. Thromb J. 2016;14:7. doi:10.1186/ s12959-016-0081-5

5. França A, De Sousa JA, Felicíssimo P, Ferreira D. [Venous thromboembolism's risk assessment: rationale, objectives, and methodology--the ARTE study]. Acta Med Port. 2011;24 Suppl 2:575-582.

6. Okuhara A, Navarro TP, Procópio RJ, Bernardes R, Oliveira L, Nishiyama MP. Incidência de trombose venosa profunda e qualidade da profilaxia para tromboembolismo venoso. Rev Col Bras Cir. 2014;41(1):2-6. doi:10.1590/s010069912014000100002

7. Ye F, Bell LN, Mazza J, Lee A, Yale SH. Variation in definitions of immobility in pharmacological thromboprophylaxis clinical trials in medical inpatients: a systematic review. Clin Appl Thromb Hemost. 2018;24(1):13-21. doi:10.1177/1076029616677802

8. Casella IB, Puech-Leão P. Generic versus branded enoxaparin in prophylaxis and treatment of vein thrombosis. Rev Assoc Med Bras (1992). 2015;61(1):44-50. doi:10.1590/1806-9282.61.01.044

9. Rassam E, Pinheiro TC, Stefan LF, Modena SF. Complicações tromboembólicas no paciente cirúrgico e sua profilaxia. Arq Bras Cir Dig. 2009;22(1):41-44. doi:10.1590/s010267202009000100009

10. Bailey PP, Miller RR, 3rd, Clemmer TP. Culture of early mobility in mechanically ventilated patients. Crit Care Med. 2009;37(10 Suppl):S429-435. doi:10.1097/ CCM.0b013e3181b6e227

11. Morris PE, Goad A, Thompson C, et al. Early intensive care unit mobility therapy in the treatment of acute respiratory failure. Crit Care Med. 2008;36(8):2238-2243. doi:10.1097/ CCM.0b013e318180b90e

12. Morris PE, Herridge MS. Early intensive care unit mobility: future directions. Crit Care Clin. 2007;23(1):97-110. doi:10.1016/j.ccc.2006.11.010

13. de Souza Penha G, Damiano AP, Carvalho TD, Lain V, Serafim JD. Mobilização precoce na fase aguda da trombose venosa profunda de membros inferiores. J Vasc Bras. 2009;8(1):77-85. doi:10.1590/s1677-54492009000100011

14. de Bastos M, Barreto SM, Caiafa JS, Rezende SM. 
[Thromboprophylaxis: medical recommendations and hospital programs]. Rev Assoc Med Bras (1992). 2011;57(1):88-99. doi:10.1590/s0104-42302011000100022

15. Carneiro JL, Targueta GP, Marino LO. [Evaluation of venous thromboembolism prophylaxis in a high complexity hospital]. Rev Col Bras Cir. 2010;37(3):204210. doi:10.1590/s0100-69912010000300008

16. Rocha AT, de Paiva EF, Lichtenstein A, et al. Tromboembolismo venoso: profilaxia em pacientes clínicos - parte I. Rev Assoc Med Bras. 2009;55(2):102-105. doi:10.1590/s0104-42302009000200007

17. Cardoso GS, Schakofski TD, Bersani-Amado LE. Profilaxia da trombose venosa profunda e tromboembolismo pulmonar: uma revisão bibliográfica. Brazilian Journal of Sugery and Clinical Research. 2014;5(2):27-30.

18. Sociedade Brasileira de Angiologia e Cirurgia Vascular. Trombose Venosa Profunda: Diagnóstico e Tratamento. 2015. Available from: http://www.sbacv.org.br/lib/media/ pdf/diretrizes/trombose-venosa-profunda.pdf. Accessed March 10, 2018.

19. Santos LR, Gardenghi G, Junior AJ. Profilaxia para Trombose Venosa Profunda em pacientes com fraturas de membro inferior internados em um hospital referência de Goiânia. Rev Pesqui Fisioter. 2017;7(1):61-69. doi:10.17267/2238-2704rpf.v7i1.1224

20. Tonioli LP, Lapa MS. Profilaxia para TEV em pacientes clínicos e cirúrgicos: recomendações atuais. Pneumologia Paulista. 2012;26(4):17-19.

21. Mota CM, da Silva VG. A segurança da mobilização precoce em pacientes críticos: uma revisão de literatura. Interfaces Científicas-Saúde e Ambiente. 2012;1(1):83-91. doi:10.17564/2316-3798.2012v1n1p83-91

22. Garcia AC, de Souza BV, Volpato DE, et al. Reality check: use of deep venous thrombosis prophylaxis: from theory to practice. J Vasc Bras. 2005;4(1):35-41. doi:10.1590/s167754492007000400008

23. Moulim JL, Sobreira ML, Malgor RD, de Abreu CR, de Araújo ESF, Palhares Neto AA. Deep venous thrombosis prophylaxis protocols comparative study: a new proposal. Rev Bras Cir Plást. 2010;25(3):415-422. doi:10.1590/S198351752011000100033

24. Testroote MJ, Wittens CH. Prevention of venous thromboembolism in patients undergoing surgical treatment of varicose veins. Phlebology. 2013;28 Suppl 1:86-90. doi:10.1177/0268355512475121

25. Partsch H. Compression therapy for deep vein thrombosis. Vasa. 2014;43(5):305-307. doi:10.1024/0301-1526/a000368

26. Sociedade Brasileira de Angiologia e de Cirurgia Vascular. Terapia de Compressão de Membros Inferiores. Projeto Diretrizes. 2011 Aug, 1-10. Available from: https:// diretrizes.amb.org.br/_BibliotecaAntiga/terapia_de_ compressao_de_membros_inferiores.pdf. Accessed March $10,2018$.

27. Konstantinides SV, Torbicki A, Agnelli G, et al. 2014 ESC guidelines on the diagnosis and management of acute pulmonary embolism. Eur Heart J. 2014;35(43):3033-3069, 3069a-3069k. doi:10.1093/eurheartj/ehu283

28. Schuren J. Compression stockings after deep vein thrombosis: where is the evidence? Veins Lymphatics. 2018;7(2):7636. doi:10.4081/vl.2018.7636
29. Prandoni P, Lensing AW, Prins $\mathrm{MH}$, et al. Below-knee elastic compression stockings to prevent the postthrombotic syndrome: a randomized, controlled trial. Ann Intern Med. 2004;141(4):249-256. doi:10.7326/0003-4819141-4-200408170-00004

30. Angoules AG. Conservative treatment of chronic venous insufficiency. J Nov Physiother. 2014;5(1):e135. doi:10.4172/2165-7025.1000e135

31. Aschwanden M, Jeanneret C, Koller MT, Thalhammer C, Bucher HC, Jaeger KA. Effect of prolonged treatment with compression stockings to prevent post-thrombotic sequelae: a randomized controlled trial. J Vasc Surg. 2008;47(5):1015-1021. doi:10.1016/j.jvs.2008.01.008

32. Urbankova J, Quiroz R, Kucher N, Goldhaber SZ. Intermittent pneumatic compression and deep vein thrombosis prevention. A meta-analysis in postoperative patients. Thromb Haemost. 2005;94(6):1181-1185. doi:10.1160/th05-04-0222

33. Arabi YM, Khedr M, Dara SI, et al. Use of intermittent pneumatic compression and not graduated compression stockings is associated with lower incident VTE in critically ill patients: a multiple propensity scores adjusted analysis. Chest. 2013;144(1):152-159. doi:10.1378/chest.12-2028

34. Arabi YM, Alsolamy S, Al-Dawood A, et al. Thromboprophylaxis using combined intermittent pneumatic compression and pharmacologic prophylaxis versus pharmacologic prophylaxis alone in critically ill patients: study protocol for a randomized controlled trial. Trials. 2016;17(1):390. doi:10.1186/s13063-016-1520-0

35. Deirmengian GK, Heller S, Smith EB, Maltenfort M, Chen AF, Parvizi J. Aspirin can be used as prophylaxis for prevention of venous thromboembolism after revision hip and knee arthroplasty. J Arthroplasty. 2016;31(10):22372240. doi:10.1016/j.arth.2016.03.031

36. Raphael IJ, Tischler EH, Huang R, Rothman RH, Hozack WJ, Parvizi J. Aspirin: an alternative for pulmonary embolism prophylaxis after arthroplasty? Clin Orthop Relat Res. 2014;472(2):482-488. doi:10.1007/s11999-0133135-Z

37. Anderson DR, Dunbar MJ, Bohm ER, et al. Aspirin versus low-molecular-weight heparin for extended venous thromboembolism prophylaxis after total hip arthroplasty: a randomized trial. Ann Intern Med. 2013;158(11):800806. doi:10.7326/0003-4819-158-11-201306040-00004

38. Matheus JP, Gomide LB, de Oliveira JG, Volpon JB, Shimano AC. Effects of neuromuscular electric stimulation during immobilization in the mechanical properties of the skeletal muscle. Rev Bras Med Esporte. 2007;13(1):55-59. doi:10.1590/s1517-86922007000100013

39. Bax M, Goldstein M, Rosenbaum P, et al. Proposed definition and classification of cerebral palsy, April 2005. Dev Med Child Neurol. 2005;47(8):571-576. doi:10.1017/ s001216220500112x

40. Crevenna R, Marosi C, Schmidinger M, Fialka-Moser V. Neuromuscular electrical stimulation for a patient with metastatic lung cancer--a case report. Support Care Cancer. 2006;14(9):970-973. doi:10.1007/s00520-006-0033-x

41. Czyrny JJ, Kaplan RE, Wilding GE, Purdy CH, Hirsh J. Electrical foot stimulation: a potential new method of deep venous thrombosis prophylaxis. Vascular. 2010;18(1):20- 


\section{7. doi:10.2310/6670.2010.00001}

42. Ravikumar R, Williams KJ, Babber A, et al. Neuromuscular electrical stimulation for the prevention of venous thromboembolism. Phlebology. 2018;33(6):367-378. doi: $10.1177 / 0268355517710130$

43. Needham DM, Truong AD, Fan E. Technology to enhance physical rehabilitation of critically ill patients. Crit Care Med. 2009;37(10 Suppl):S436-441. doi:10.1097/ CCM.0b013e3181b6fa29

44. Needham DM. Mobilizing patients in the intensive care unit: improving neuromuscular weakness and physical function. JAMA. 2008;300(14):1685-1690. doi:10.1001/ jama.300.14.1685

45. Velar CM, Junior GF. Ortostatismo passivo em pacientes comatosos na UTI - Um estudo preliminar. Rev Neurocienc. 2008;16(1):16-19. doi:10.34024/rnc.2008.v16.8658

46. Nici L, Donner C, Wouters E, Zuwallack R, Ambrosino N, Bourbeau J, et al. American Thoracic Society/European Respiratory Society statement on pulmonary rehabilitation. Am J Respir Crit Care Med. 2006; 173(12):1390-413. doi: 10.1164/rccm.200508-1211ST

47. Dantas CM, Silva PF, de Siqueira FH, et al. Influence of early mobilization on respiratory and peripheral muscle strength in critically ill patients. Rev Bras Ter Intensiva. 2012;24(2):173-178.

48. Pinheiro AR, Christofoletti G. Motor physical therapy in hospitalized patients in an intensive care unit: a systematic review. Rev Bras Ter Intensiva. 2012;24(2):188-196. doi:10.1590/s0103-507x2012000200016

49. Porta R, Vitacca M, Gilè LS, et al. Supported arm training in patients recently weaned from mechanical ventilation. Chest. 2005;128(4):2511-2520. doi:10.1378/ chest.128.4.2511

50. Capodaglio P, Sartorio F, Colombo R, Franchignoni F. [Cycle ergometers in rehabilitation medicine: technical characteristics and selection criteria]. G Ital Med Lav Ergon. 2007;29(4):942-948.

51. Neser RA, Capasso Filho M, Homa CM. Implante de filtro de veia cava inferior guiado por ultra-som: relato de dois casos. J Vasc Bras. 2006;5(1):71-73. doi:10.1590/s167754492006000100014

52. Coimbra R, Constantini T. Retrievable inferior vena cava filter use in trauma: has the fever broken? J Vasc Bras. 2009;8(3):204-246. doi:10.1590/s1677-54492009000300003

53. Paffrath $\mathrm{T}$, Wafaisade A, Lefering $\mathrm{R}$, et al. Venous thromboembolism after severe trauma: incidence, risk factors and outcome. Injury. 2010;41(1):97-101. doi:10.1016/j.injury.2009.06.010

54. Bertanha M, Sobreira ML, Moura R, et al. Simultaneous placement of filters in inferior vena cava and superior vena cava. J Vasc Bras. 2013;12(3):226-229. doi:10.1590/ jvb.2013.037

55. Fonseca Filho VL, Oliveira FAC. Filtro de veia cava-tipos, indicações, técnica e resultados. In: Brito CJ, ed. Cirurgia Vascular: Cirurgia Endovascular, Angiologia. 2nd ed. Revinter; 2008:1727-1738.

56. Kinney TB. Update on inferior vena cava filters. J Vasc Interv Radiol. 2003;14(4):425-440. doi:10.1097/01. rvi.0000064860.87207.77

57. Kearon C, Kahn SR, Agnelli G, Goldhaber S, Raskob GE, Comerota AJ. Antithrombotic therapy for venous thromboembolic disease: American College of Chest Physicians evidence-based clinical practice guidelines. Chest. 2008;133(6 Suppl):454S-545S. doi:10.1378/ chest.08-0658

58. Yoshimura N, Hori Y, Horii Y, Takano T, Ishikawa H, Aoyama H. Where is the most common site of DVT? Evaluation by CT venography. Jpn J Radiol. 2012;30(5):393397. doi:10.1007/s11604-012-0059-6

59. Hann CL, Streiff MB. The role of vena caval filters in the management of venous thromboembolism. Blood Rev. 2005;19(4):179-202. doi:10.1016/j.blre.2004.08.002

60. Kuo HC, Liu FL, Chen JT, Cherng YG, Tam KW, Tai YH. Thromboembolic and bleeding risk of periprocedural bridging anticoagulation: a systematic review and metaanalysis. Clin Cardiol. 2020;43(5):441-449. doi:10.1002/ clc. 23336

61. Shaw JR, LiN, Vanassche T, et al. Predictors of preprocedural direct oral anticoagulant levels in patients having an elective surgery or procedure. Blood Adv. 2020;4(15):35203527. doi:10.1182/bloodadvances.2020002335

62. Torbicki A, Perrier A, Konstantinides S, et al. Guidelines on the diagnosis and management of acute pulmonary embolism: the Task Force for the Diagnosis and Management of Acute Pulmonary Embolism of the European Society of Cardiology (ESC). Eur Heart J. 2008;29(18):2276-2315. doi:10.1093/eurheartj/ehn310

63. Uso de filtros de veia cava. J Bras Pneumol. 2010;36(Suppl 1):39-39. doi:10.1590/s1806-37132010001300013 